\title{
The evolution of natriuretic peptide augmentation in management of heart failure and the role of sacubitril/ valsartan
}

\author{
Srikanth Yandrapalli, Wilbert S. Aronow, Pratik Mondal, David R. Chabbott
}

Cardiology Division, Department of Medicine, Westchester Medical Center/New York Medical College, Valhalla, NY, USA

Submitted: 30 March 2016

Accepted: 11 May 2016

Arch Med Sci 2017; 13, 5: 1207-1216

DOI: https://doi.org/10.5114/aoms.2017.68813

Copyright $\odot 2017$ Termedia \& Banach

\begin{abstract}
A bstract
Heart failure (HF) is one of the leading causes of morbidity, mortality, and health care expenditures in the US and worldwide. For three decades, the pillars of treatment of HF with reduced ejection fraction (HFrEF) were medications that targeted the sympathetic nervous system (SNS) and the renin-angiotensin-aldosterone system (RAAS). Prior attempts to augment the natriuretic peptide system (NPS) for the management of HF failed either due to lack of significant clinical benefit or due to the unacceptable side effect profile. This review article will discuss the NPS, the failure of early drugs which targeted the NPS as therapies for HF, and the sequence of events which led to the development of sacubitril plus valsartan (Entresto; LCZ696; Novartis). LCZ696 has been shown to be superior to the standard of care available for treatment of HFrEF in several substantial hard endpoints including heart failure hospitalizations, cardiovascular mortality, and all-cause mortality.
\end{abstract}

Key words: sacubitril/valsartan, Entresto, LCZ696, heart failure with reduced ejection fraction, natriuretic peptide system.

\section{Introduction}

Heart failure (HF) is the inability of the heart to pump an adequate supply of blood to meet the demands of the body. The HF is a clinical syndrome characterized by impaired myocardial function and progressive maladaptive neurohormonal activation of the cardiovascular and renal systems leading to circulatory insufficiency. The HF is one of the leading causes of morbidity, mortality, and health care expenditures in the US and worldwide [1-4]. The HF is classified on the basis of ejection fraction (EF) into HF with reduced $\mathrm{EF}$ (HFrEF) with an $\mathrm{EF}<50 \%$, and $\mathrm{HF}$ with preserved $E F(H F p E F)$ with an $E F \geq 50 \%$. Over the last century there has been significant progress in identifying the neurohormonal systems responsible for the development of heart failure including the sympathetic nervous system (SNS) and the renin-angiotensin-aldosterone system (RAAS) (Figure 1). Beta-adrenergic blockers ( $\beta$-blockers) targeting the SNS, angiotensin-converting enzyme inhibitors (ACEls), angiotensin receptor blockers (ARBs), and aldosterone antagonists targeting the RAAS have become the cornerstone of medical therapy for chronic HFrEF

\author{
Corresponding author: \\ Prof. Wilbert S. Aronow MD, \\ FACC, FAHA \\ Cardiology Division \\ New York Medical College \\ Macy Pavilion, Room 141 \\ Valhalla, NY 10595, USA \\ Phone: (914) 493-5311 \\ Fax: (914) 235-6274 \\ E-mail: wsaronow@aol.com
}


[5]. These drugs have been shown to reduce both morbidity and mortality [5]. However, with improved survival of patients with acute myocardial infarction and a growing elderly population, heart failure will continue to increase in prominence as a major health issue in the United States and the world [1].

The newest and most promising medication for the treatment of chronic HFrEF is sacubitril/ valsartan (LCZ696), a drug that targets the natriuretic peptide system (NPS) in addition to the RAAS (Figure 1) [6]. This article will briefly discuss the NPS, explain the reasons behind the failure of the early agents that targeted the NPS, and will then proceed to review the development and current physiological understanding of LCZ696 in the treatment of HF.

\section{Treatment of heart failure}

The HF as a disease entity was first described in texts dating back to ancient Egypt, Greece, and India [7]. The first medical therapy for HF was digitalis, an extract from the Foxglove plant [8]. From the early 1900s, diuretics were used in addition to digoxin [9]. These medications treated the symp- toms of HF and did not target the neuro-hormonal pathways causing the HF syndrome. Since then, ACEIs [10, 11], $\beta$-blockers [12-14], aldosterone antagonists [15-17], ARBs [18, 19], and the combination of isosorbide dinitrate and hydralazine [20] have been approved for the treatment of HFrEF.

\section{Natriuretic peptide system (NPS)}

Currently, the cornerstones of HF therapy are drugs that modulate the SNS and RAAS. However, since the early 1980s, there has been significant clinical interest in the NPS as a key hormonal pathway critical to the development and possible treatment of HF. Natriuretic peptides (NPs) are endogenous protein molecules that cause urinary sodium excretion, with the exception being C-type NP, which does not exert a marked effect on sodium or water excretion [21]. The NPS consists of the three main NPs secreted from the heart: atrial natriuretic peptide (ANP), B-type natriuretic peptide (BNP), and C-type natriuretic peptide (CNP) [22]. ANP is primarily secreted from the atria, BNP from the ventricles and CNP from endothelial cells and cardiac fibroblasts [22]. ANP and BNP are circulating hormones released from the atrium and ven-

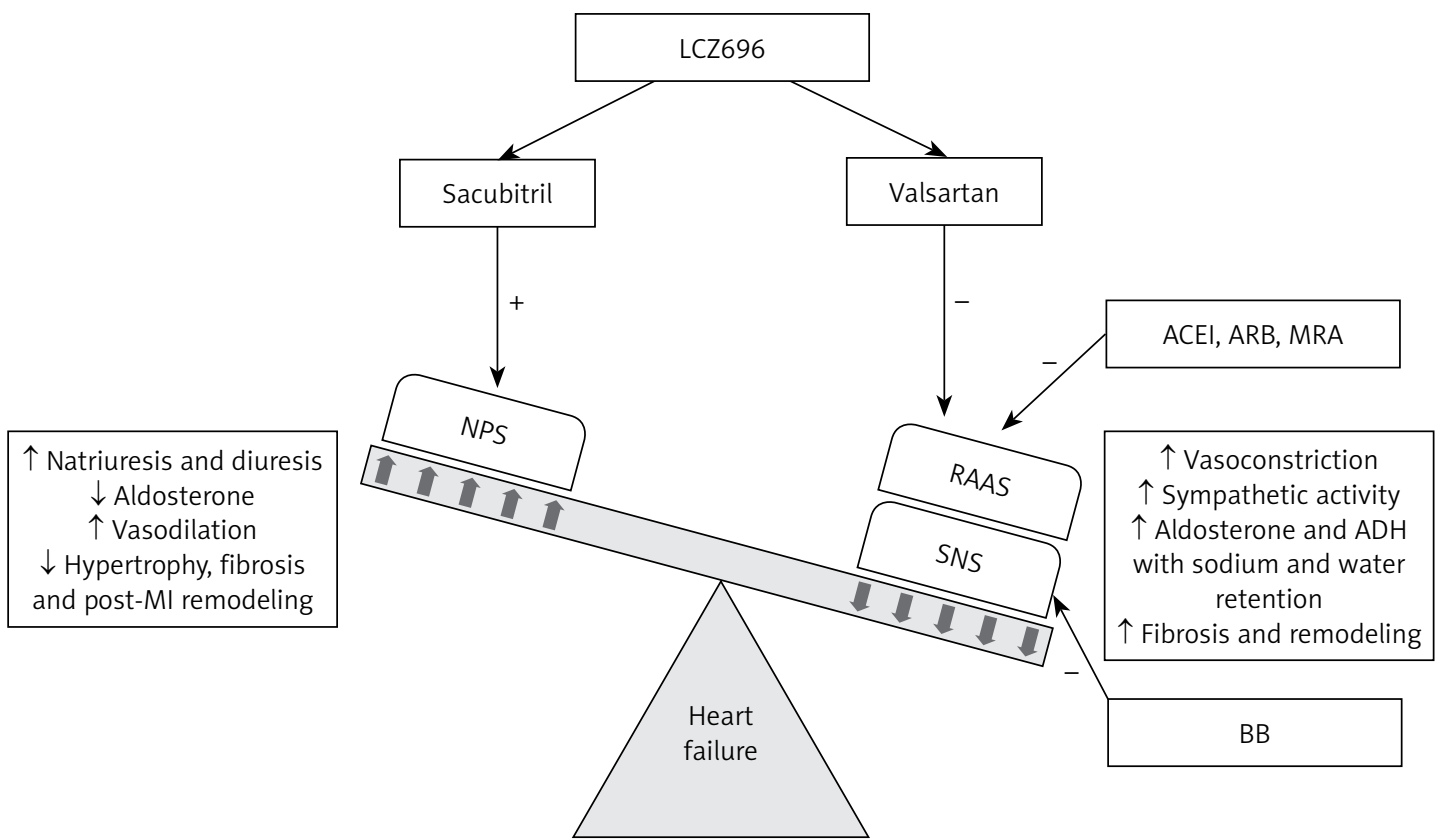

Figure 1. Neuro-hormonal interactions in heart failure and their role in contributing to the progression of heart failure. Heart failure activates the SNS and the RAAS, which leads to increased sympathetic tone and vasoconstriction, thereby increasing the afterload on the failing heart. RAAS activation leads to an increase in secretion of aldosterone and ADH causing fluid retention, edema, and fibrotic changes in the failing myocardium. Together, the SNS and the RAAS result in pathophysiological and clinical worsening of HF. ACEI, ARB, MRA, and BB reduce the effects of the RAAS and the SNS. The failing heart also activates the NPS, which promotes sodium and water excretion, vasodilatation, and decreased aldosterone secretion, and inhibits fibrotic changes in the failing myocardium. The effects of the NPS are antagonistic to those of the SNS and the RAAS. LCZ696 acts by augmenting the NPS and inhibiting the RAAS, thereby improving the symptoms and inhibiting the progression of HF

NPS - natriuretic peptide system, RAAS - renin-angiotensin-aldosterone system, SNS - sympathetic nervous system, $A C E I$ - angiotensin converting enzyme inhibitor, $A R B$ - angiotensin receptor blocker, MRA - mineralocorticoid receptor antagonist, $B B$ - $\beta$-adrenergic blocker, $A D H$ - antidiuretic hormone, "+" indicates augmentation, "-" indicates inhibition, "个” indicates increase, “ $\downarrow$ " indicates decrease. 
tricles in response to stretch and fluid overload, and these hormones counteract the volume overloaded state by promoting natriuresis, diuresis, vasodilation, and RAAS blockade via aldosterone and renin inhibition [22]. ANP and BNP decrease preload via diuresis and decrease afterload via vasodilation and RAAS blockade. CNP acts locally and exhibits vasodilatory and anti-remodeling effects on the myocardium [23]. These hormonal actions prevent the classic pathologic structural changes associated with HF including cardiovascular remodeling, ventricular hypertrophy, and fibrosis [24].

In contrast to the detrimental effects of activation of the SNS and the RAAS, activation of the NPS appears to have a beneficial role in the prevention of progression of HF. Understanding of the beneficial effects of NPS prompted the creation of human synthetic ANP (carperitide) and human recombinant BNP (nesiritide). Intravenous infusion of carperitide is used as a treatment for acute decompensated heart failure in Japan without good evidence to support this practice [25]. Although infusions of nesiritide have shown promising results in a few studies $[26,27]$, nesiritide failed to show significant clinical benefit in larger trials [28-30]. The ASCEND-HF (Acute Study of Clinical Effectiveness of Nesiritide and Decompensated Heart Failure) trial compared nesiritide and placebo in the treatment of acute decompensated heart failure. The results of this trial showed no significant benefit in early dyspnea relief, 30day mortality or readmission rates in the nesiritide group, but showed an increase in hypotension [28]. On the basis of the available data the NPs were widely accepted as biomarkers of HF but not therapeutic options [5].

\section{Neprilysin inhibition}

When intravenous infusion of NPs did not demonstrate significant clinical significance in treating $\mathrm{HF}$, the focus shifted to developing inhibitors of enzymes that degrade endogenous NPs. Clearance of circulating NPs is via receptor-mediated clearance and enzymatic degradation by extracellular proteases [31]. Neprilysin (NEP) is a large membrane-bound neutral endopeptidase responsible for cleaving NPs [31]. NEP, also known as enkephalinase, atriopeptidase, EC 3.4.24.11, and CD10 [31], is present in many tissues [24, 32], and is most abundant in the renal cortex [33]. NEP contributes to the extremely short half-life of ANP of approximately $2 \mathrm{~min}$ [33]. ANP and CNP are more readily degraded, whereas BNP is relatively resistant to the action of NEP [34]. From a physiologic standpoint, inhibiting NEP represented an approach to augment endogenous NP levels and activity.
Thiorphan, an NEP inhibitor (NEPI), was synthesized in 1980 [35], and subsequent studies in animals [36] and humans [37] demonstrated that NEP inhibition increased ANP levels with associated natriuresis, diuresis and blood pressure reduction. Additionally, NEP inhibition suppressed the activation of aldosterone [38], demonstrating the important interaction between NPS and the RAAS [33]. In a study of 9 patients with severe chronic $\mathrm{HF}(\mathrm{EF}<30 \%)$, intravenous candoxatrilat (an NEPI) increased circulating ANP, improved natriuresis and diuresis, and reduced right atrial pressure and pulmonary capillary wedge pressure, without affecting the arterial blood pressure [39]. The positive results from this trial prompted investigations using oral NEPIs. However, studies of oral ecadotril $[40,41]$ and oral candoxatril [42] failed to show significant benefit in patients with chronic HF and essential hypertension, respectively. A few studies showed inconsistent effects of NEPIs on blood pressure [42, 43].

In addition to degrading NPs, NEP also degrades a large number of other vasoactive peptides including vasodilators such as adrenomedullin and bradykinin and vasoconstrictors such as angiotensin I, II, and endothelin-1 [44, 45]. The beneficial effects of augmenting endogenous NPs were offset by the NEPI-mediated enhancement of vasoconstrictor substances, importantly angiotensin II, and, thereby, enhancing the RAAS. Based on these observations, it was evident that lone NEP inhibition showed little effect on blood pressure and only modest benefits [45] in the treatment of HF (Figure 2).

\section{The rise and fall of omapatrilat}

The rational solution to this dilemma was to further inhibit angiotensin II in addition to NEP in an effort to prevent the detrimental effects of NEP inhibition on the RAAS. Preliminary animal studies with combined selective NEPI and captopril (an ACEI) showed greater blood pressure reduction [46], improved systemic hemodynamics [47], and improved left atrial filling pressures [48].

After the synthesis of an orally active combined ACEI-NEPI in 1994 [49], multiple studies examined the effects of an orally active vasopeptidase inhibitor - omapatrilat. This class of drugs was referred to as vasopeptidase inhibitors as they have dual inhibitory effects on 2 key enzymes involved in the metabolism of vasoactive peptides [50]. Omapatrilat improved natriuresis, diuresis, left ventricular EF, and functional class in chronic HF patients [51]. The IMPRESS (Inhibition of Metallo Protease by BMS-186716 in a Randomized Exercise and Symptoms Study in Subjects With Heart Failure) trial, a phase II randomized clinical trial that compared omapatrilat with lisinopril in $573 \mathrm{HFrEF}$ pa- 


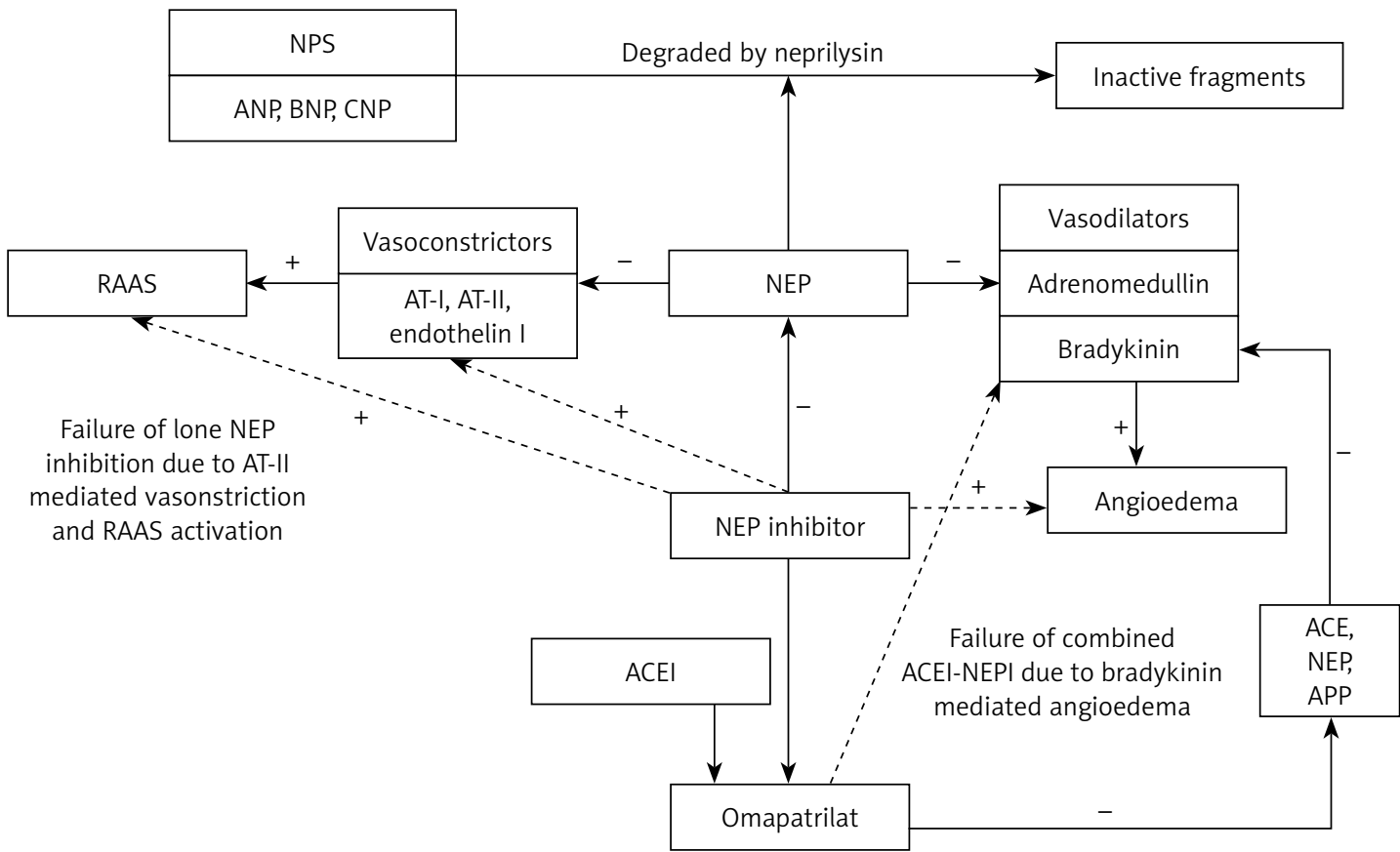

Figure 2. Physiological mechanisms behind the failure of lone neprilysin inhibition, and combined angiotensin converting enzyme - neprilysin inhibitors, as potential therapies in the management of heart failure. The beneficial effects of augmenting endogenous natriuretic peptides with NEPI were offset by the NEP-mediated enhancement of vasoconstrictor substances, especially AT-II, which enhanced the RAAS pathway. Bradykinin is inactivated by various enzymes including ACE, NEP, and APP, all of which are inhibited by omapatrilat. The synergism of ACE inhibition with NEP inhibition led to a large increase in the levels of bradykinin, thereby causing angioedema

NPS - natriuretic peptide system, ANP - A-type natriuretic peptide, BNP - B-type natriuretic peptide, CNP - C-type natriuretic peptide, RAAS - renin-angiotensin-aldosterone system, AT-I - angiotensin I, AT-II - angiotensin II, NEP - neprilysin, $A C E$ - angiotensin converting enzyme, APP - aminopeptidase $P, A C E I$ - angiotensin converting enzyme inhibitor, NEPI - neprilysin inhibitor, "+" indicates increase/augmentation, "-" indicates inhibition, continuous line indicates direct action, dotted line indicates indirect action.

tients, showed that omapatrilat had a non-significant benefit in the composite of first occurrence of death or admission for worsening HF $[52,53]$.

The OVERTURE (Omapatrilat Versus Enalapril Randomized Trial of Utility in Reducing Events) trial was a phase III randomized double-blind trial that compared omapatrilat with enalapril in 5770 patients with New York Heart Association (NYHA) class II-IV HF for a mean duration of 14.5 months [54]. Results from the OVERTURE trial showed that omapatrilat was neither superior nor inferior to enalapril in reducing the primary endpoint of combined all-cause mortality and HF hospitalizations requiring intravenous treatment [54]. Post hoc analysis using a broader definition for HF hospitalizations (as used in the Studies of Left Ventricular Dysfunction (SOLVD) treatment trial) showed a $11 \%$ reduction (nominal $p=0.012$ ) in the primary endpoint [54]. Secondary analysis favored omapatrilat in reducing cardiovascular-related death or cardiovascular-related hospitalizations [54]. Although the adverse effect profiles were similar, angioedema was more frequent in patients taking omapatrilat $(0.8 \%)$ compared to the enalapril group (0.5\%). Encouraging results from the OVERTURE trial prompted larger clinical trials.
The Omapatrilat Cardiovascular Treatment vs. Enalapril (OCTAVE) trial was a randomized, controlled, double-blind trial that compared omapatrilat and enalapril for 24 weeks in 25,302 hypertensive patients [55]. Although omapatrilat significantly lowered blood pressure, angioedema was more frequent with omapatrilat $(2.17 \%)$ than with enalapril $(0.68 \%)$, particularly in African-Americans (5.53\% vs $1.62 \%$ ) [55].

ACEI can potentially cause angioedema by inhibiting the metabolism of bradykinin $[56,57]$. Subsequently, it was identified that omapatrilat also inhibits aminopeptidase P(APP), which is involved in bradykinin metabolism [58]. Bradykinin is inactivated by various enzymes including ACE, NEP, and APP, all of which are inhibited by omapatrilat [59]. The synergism of ACE inhibition with NEP inhibition led to a large increase in the levels of bradykinin [59], causing angioedema, a concern that stalled the approval and further development of a combined ACEI-NEPI as a therapy for HF (Figure 2).

\section{LCZ696 and the early clinical trials}

The discovery of the role of NPS in the progression of HF and the idea of combined RAAS and 
NEP inhibition remained exciting and promising, but the trials discussed demonstrated that omapatrilat was associated with angioedema [55]. The logical solution to this problem was a combination of an ARB and NEPI which would inhibit the RAAS and enhance the NPS without inhibiting ACE or APP. By using this combination, the endogenous bradykinin would be metabolized by the uninhibited ACE, thereby not greatly increasing the risk of angioedema. Results from an animal study published later supported this hypothesis [60].

LCZ696 is a novel, orally active, first-in-class angiotensin receptor-neprilysin inhibitor (ARNI) which combines valsartan (an ARB) and sacubitril in a $1: 1$ ratio [61]. Sacubitril (AHU377) is a prodrug, which upon ingestion is rapidly metabolized to an active NEPI moiety, LBQ657 [61]. Phase I and II studies of LCZ696 showed that after oral administration of LCZ696, peak plasma concentrations were reached rapidly for valsartan (1.6-4.9 h), sacubitril (0.5-1.1 h), and its active moiety LBQ657 (1.8-3.5 h), followed by an acute blood pressure reduction [61]. LCZ696 treatment was associated with increases in plasma ANP and cGMP, diuresis, blood pressure reduction, increased renin concentration and activity, and increased angiotensin II levels, providing evidence for NEP inhibition and angiotensin receptor blockade [61, 62]. LCZ696 was considered safe and well tolerated, and data from these studies supported its further clinical development for hypertension and HF.

A phase III trial compared LCZ696 with valsar$\tan$ in 1328 subjects with mild to moderate hypertension [63]. The primary endpoint of this study was the mean difference across the 3 single-dose pairwise comparisons of LCZ696 versus valsar$\tan (100 \mathrm{mg}$ vs. $80 \mathrm{mg}, 200 \mathrm{mg}$ vs. $160 \mathrm{mg}$, and $400 \mathrm{mg}$ vs. $320 \mathrm{mg}$ ) in mean sitting diastolic blood pressure during the 8-week treatment period. Part of the study population received either AHU377 or placebo once daily. Data from this study showed that reduction in systolic, diastolic, and pulse pressures, both sitting and ambulatory, was greater with LCZ696 than with either valsartan or AHU377 [63]. A similarly designed trial comparing LCZ696 with placebo in 389 Asian subjects with mild to moderate hypertension achieved similar results [64]. Although LCZ696 was well tolerated in both trials without reports of angioedema, only a small percentage of study patients were black $[63,64]$, in whom the incidence of angioedema was greater according to the OCTAVE trial [65]. Also the generalizability of these data to patients with HF is limited because such patients were excluded from these trials.

The PARAMOUNT (Prospective comparison of ARNI with ARB on Management of heart failUre with preserved ejectioN fracTion) trial was a phase II randomized double-blind trial of 301 patients with NYHA class II-IV HFpEF that compared N-terminal pro BNP (NT-proBNP) levels after 12 weeks of treatment with either LCZ696 or valsartan [65]. NT-proBNP is a precursor molecule for BNP and is not a substrate for NEPI [66]. Baseline NT-proBNP was greater than $400 \mathrm{pg} / \mathrm{ml}$ in the study population. At 12 weeks, NT-proBNP was significantly reduced in the LCZ696 group (hazard ratio $(H R)=0.77$, $p=0.005)$. After 36 weeks of treatment, the LCZ696 group demonstrated a decrease in left atrial volume and size and greater improvement in NYHA functional class. The adverse event rate was similar in both groups. Post hoc analysis suggested that the NT-proBNP lowering effect of LCZ696 was independent of systolic blood pressure reduction [67]. Encouraging results from these early trials prompted further larger trials.

\section{The paradigm-heart failure trial}

The medical and pharmaceutical community looked forward to further studies investigating the clinical benefit of LCZ696 in HF patients. The PARADIGM-HF (Prospective comparison of ARNI with ACEI to Determine Impact on Global Mortality and morbidity in Heart Failure) was a phase III double-blind trial that randomized 8442 patients with NYHA class II-IV HF and an EF of $\leq 40 \%$ (later amended to $\leq 35 \%$ ) to receive twice daily dosing of either $200 \mathrm{mg}$ of LCZ696 or $10 \mathrm{mg}$ of enalapril in addition to standard medical therapy for HF [6]. Enalapril was chosen as it was the most widely studied RAAS blocker in patients with chronic HFrEF, and the target dose of enalapril in PARADIGM-HF was similar to the dose used in the SOLVD treatment trial. The majority of the study population was receiving $\beta$-blockers and mineralocorticoid receptor antagonists. The primary endpoint was a composite of death from cardiovascular causes or hospitalization for HF.

The PARADIGM-HF trial was initiated without a phase-II safety trial and hence the investigators employed steps to test the tolerability of LCZ696 before randomization. Patients taking any dose of ACEI or ARB were considered for participation in the study, but prior to screening, patients were required to be on a stable dose of an ACEI or an ARB that was the therapeutic equivalent of $10 \mathrm{mg}$ of enalapril daily for at least 4 weeks. Patients that met screening criteria then entered an initial run-in period where they were switched from their prior ARB or ACEI to $10 \mathrm{mg}$ of enalapril twice daily for 2 weeks. If this regimen was tolerated, a second run-in period was implemented where participants were started on a single blind treatment of LCZ696 for an additional 4-6 weeks. Initially the dose of LCZ696 was 100 mg twice daily, which was increased to $200 \mathrm{mg}$ twice daily. If participants tolerated both the study medications (LCZ696 and 
enalapril), they were then randomly assigned to double-blind treatment with either enalapril 10 mg twice daily or LCZ696 200 mg twice daily. This methodology allowed the investigators to obtain data regarding the safety and tolerability of target doses of the study drugs.

The study was stopped early after a median follow-up of 27 months due to the significant clinical benefit observed with LCZ696, which at that time met the pre-specified cutoff for an immense benefit. At 27-month follow-up, LCZ696 was associated with a $20 \%(H R=0.80, p<0.001)$ decrease in the primary endpoint compared to enalapril (absolute risk reduction (ARR) 4.7\%). The number needed to treat over 27 months to prevent 1 occurrence of a primary endpoint was 21 . When compared to enalapril, LCZ696 reduced death from any cardiovascular cause by $20 \%$ (ARR 3.2\%, HR $=0.8$, $p<0.001)$ and HF hospitalizations by $21 \%$ $(\mathrm{HR}=0.79, p<0.001)$, and improved the symptoms and quality of life as measured on the Kansas City Cardiomyopathy Questionnaire. There was a 16\% $(\mathrm{HR}=0.84, p<0.001)$ reduction in all-cause mortality in the LCZ696 arm. In terms of side effects, $14 \%$ of patients receiving LCZ696 experienced hypotension compared to $9 \%$ in the enalapril group $(p<0.001)$. However, the number of patients who discontinued therapy due to hypotension was not significantly different $(0.9 \%$ in the LCZ696 group vs. $0.7 \%$ in the enalapril group). Non-serious angioedema occurred more frequently in the LCZ696 group although the difference was not significant (19 cases vs. 10 cases in the enalapril group). Significantly fewer patients developed cough (11.3\% in the LCZ696 group vs. $14.3 \%$ in the enalapril group, $p<0.001)$, elevated serum potassium $>6.0 \mathrm{mmol} / \mathrm{l}$ ( $4.3 \%$ in the LCZ696 group vs. $5.6 \%$ in the enalapril group, $p=0.007)$, or elevated serum creatinine $\geq 2.5 \mathrm{mg} / \mathrm{dl}$ (3.3\% in the LCZ696 group vs. $4.5 \%$ in the enalapril group, $p=0.007$ ) in the LCZ696 group.

\section{Additional analysis of the paradigm-heart failure trial}

The PARADIGM-HF investigators also compared the effects of LCZ696 with putative placebos using the treatment arms of the SOLVD treatment trial and the Candesartan in Heart Failure-Assessment in Reduction in Mortality and Morbidity-Alternative (CHARM-Alternative) trial as references for comparison with enalapril (an ACEI) and candesartan (an ARB), respectively [68]. For the primary composite outcome of cardiovascular death or HF hospitalization in the PARADIGM-HF trial, the relative risk reduction with LCZ696 versus a putative placebo from the SOLVD treatment trial was $43 \%$ ( $p<0.0001)$ with similarly large effects on cardiovascular death (34\%; $p<0.0001)$, heart failure hospitalization (49\%; $p<0.0001)$, and all-cause mortality (28\%; $p<0.0001)$. Putative placebo analyses based on the CHARM-Alternative trial showed relative risk reductions of $39 \%$ ( $p<0.0001)$ for the composite outcome of cardiovascular death or heart failure hospitalization, $32 \%(p<0.0001)$ for cardiovascular death, $46 \%$ $(p<0.0001)$ for heart failure hospitalization, and $26 \%(p<0.0001)$ for all-cause mortality [68].

Secondary analyses of data from the PARADIGM$\mathrm{HF}$ trial were also encouraging. When compared to enalapril, LCZ696 exhibited additional clinical benefits in parameters that quantify HF disease progression, including reduced worsening of NYHA functional class ( $\geq 1$ class) at 1 year $(p=0.023)$, reduced need for intensification of medical treatment of $\mathrm{HF}(\mathrm{HR}=0.84, p=0.003)$ and reduced requirement of intensive care (18\% rate reduction; $p=0.005)$ or intravenous inotropic support (31\% risk reduction, $p<0.001$ ) [69]. LCZ696 was associated with significant reductions in emergency department visits $(\mathrm{HR}=0.66 ; p=0.001)$ and $23 \%$ fewer hospitalizations for worsening HF $(p<0.001)$ [69]. Significant reductions in the levels of NT-proBNP and troponins were observed, which indicates reduced heart stress. Non-significant reductions in the need for implantation of a HF device and cardiac transplantation were also observed [69]. LCZ696 was superior to enalapril in reducing both sudden cardiac death $(H R=0.80, p=0.008)$ and death from worsening heart failure $(H R=0.79$, $p=0.034$ ), independent of whether the patient had an implantable cardioverter-defibrillator [70]. The superiority of LCZ696 over enalapril was apparent irrespective of glycemic status [71], left ventricular EF [72], HF risk scores [73], systolic blood pressure [74], and age [75].

\section{LCZ696 investigated at the tissue level}

Investigators examined the mechanistic actions of LCZ696 at the tissue level. Von Lueder et al. randomized post-myocardial infarction adult male Sprague-Dawley rats to treatment for 4 weeks with LCZ696 or a vehicle [76]. At the conclusion of the study, the LCZ696 group demonstrated higher left ventricular EF and function, lower left ventricular end diastolic diameter, and lower heart mass. Additionally, the LCZ696 group had markedly reduced fibrosis in the peri-infarct area and remote myocardium, which can be interpreted as reduced cardiac remodeling. This study demonstrated the ARNI-mediated inhibition of hypertrophy and fibrosis leading to attenuation of cardiac remodeling and myocardial dysfunction. Suematsu et al. investigated the effects of LCZ696 therapy in diabetic mice with HFrEF in comparison with valsartan or control [77]. In this study, LCZ696 improved cardiac function with the reduc- 
tion of fibrosis. The investigators attributed this to the suppression of local transforming growth factor- $\beta$ by the sacubitril moiety of LCZ696. These studies further support the pathophysiological basis for the beneficial effects of LCZ696 observed in the PARADIGM-HF trial.

\section{Criticism of the PARADIGM-HF trial}

The PARADIGM-HF trial is not without criticism, especially in regards to the study population. The study population in the PARADIGM-HF trial was predominantly white (66\%), male (78\%), NYHA functional class II HF (70\%), and had a mean age of 64 years. Only 60 patients $(<1 \%)$ had NYHA functional class IV HF at baseline, and only $5 \%$ of the study population was black. These factors might reduce the generalizability of the data from the trial as HF patients are usually older individuals with varying NYHA functional class. In the United States population, non-Hispanic black patients have a higher rate of HF-related mortality as compared to others [4]. In the OCTAVE trial, black patients had an increased frequency of angioedema with omapatrilat [55]. The lower proportion of black patients in the PARADIGM-HF trial may have limited the ability of this trial to detect a significant difference in the frequency of angioedema with LCZ696.

It is also important to consider the high dropout rate of $20 \%$ during the run-in phases in the study [6]. This dropout rate may reduce the generalizability of the study to the target patient population. Physicians should thereby be cautious in selecting patients for treatment with LCZ696, as a significant number of HF patients may not be able to tolerate the drug, and a run-in period is not feasible in regular clinical practice.

Lastly, NEP plays a critical role in maintaining the homeostasis of amyloid- $\beta$ peptide $(A \beta)$ in the brain [78]. NEPI might lead to accumulation of $A \beta$ in the brain, favoring the development of Alzheimer's dementia [79]. Although the incidence of cognition-related adverse effects was not increased by LCZ696 in the PARADIGM-HF trial [6], the duration of the trial was not long enough to assess this problem. Such data should be available from the PARAGON-HF (Prospective comparison of angiotensin receptor-neprilysin inhibitor with ARB Global Outcomes in HF with preserved ejection fraction) trial (NCT01920711), which includes serial cognitive function testing in its design. Also phase IV safety data of LCZ696 might shed more light on this association.

\section{Current role of LCZ696 in heart failure and the future of LCZ696}

The United States Food and Drug Administration approved LCZ696 for the treatment of HF.
Although the drug is not yet approved for clinical use in Canada, the Canadian HF guidelines recommend the use of LCZ696 in place of an ACEI or an ARB in patients with mild to moderate $\mathrm{HF}$, an ejection fraction $<40 \%$, an elevated natriuretic peptide level or hospitalization for HF in the past 12 months, serum potassium $<5.2 \mathrm{mmol} / \mathrm{l}$, and an estimated glomerular filtration rate $\geq 30 \mathrm{ml} / \mathrm{min}$ and treated with appropriate doses of guideline-directed medical therapy, with close surveillance of serum potassium and creatinine (Conditional Recommendation; High-Quality Evidence) [80].

Further studies are testing LCZ696 on more selective patient populations. The PARAMETER (Prospective Comparison of an Angiotensin-Receptor Neprilysin Inhibitor With an Angiotensin-Receptor Blocker Measuring Arterial Stiffness in the Elderly) study was designed to assess the short-term (12 weeks) and long-term (52 weeks) effects of LCZ696 compared with olmesartan (an ARB), on measures of central aortic hemodynamics and arterial stiffness in older patients with systolic hypertension and an increased pulse pressure [81]. The study met the primary endpoint of significant reduction in central aortic systolic pressure with 12 weeks monotherapy in the LCZ696 group compared to the olmesartan group, although this significance did not persist at 52 weeks [81]. The phase III PARAGON-HF trial is currently recruiting participants to evaluate the efficacy and safety of LCZ696 compared to valsartan on morbidity and mortality in NYHA class II-IV HF patients with a left ventricular EF > 45\% (ClinicalTrials.gov NCT01920711). This trial is based on the results from the PARAMOUNT trial. The UK Heart and Renal Protection III (UK HARP-III) trial (ISRCTN 11958993) will compare LCZ696 against irbesartan (an ARB) in patients with proteinuric chronic kidney disease to assess the short-term safety and efficacy of LCZ696 in this population [82]. If the results from the UK HARP-III trial favor LCZ696, longer duration studies to evaluate the effects of LCZ696 in delaying the progression of CKD to end-stage renal disease can be planned. Such beneficial effects can improve outcomes of HF patients with concomitant CKD.

\section{Conclusions}

The treatment of HF has been revolutionized with medications physicians are familiar with and trust such as the $\beta$-blockers, the ACEIs, the ARBs and aldosterone antagonists. Despite pharmacological advances, HF continues to increase in incidence and remains a leading cause of morbidity and mortality and economic burden. In this scenario, there is definitely a need for newer therapies that can reduce the burden of HF on the community. Although the initial attempts of NP 
enhancement for HF management have failed, the combination RAAS inhibitor and NPS enhancer sacubitril/valsartan performed significantly better than the current standard of care ACEI in the PARADIGM-HF trial. Although one trial might not be sufficient to change the guidelines, the results from the PARADIGM-HF trial provide affirmation that targeting the NPS in addition to the SNS and the RAAS provides substantial benefit to patients with HFrEF. Further large trials testing LCZ696 on specific patient populations will provide more data regarding the beneficial effects of combining NPS augmentation with RAAS inhibition in patients with cardiovascular disease.

\section{Conflict of interest}

The authors declare no conflict of interest.

\section{References}

1. Braunwald E. The war against heart failure: the Lancet lecture. Lancet 2015; 385: 812-24.

2. Mozaffarian D, Benjamin EJ, Go AS, et al. Heart disease and stroke statistics-2016 update: a report from the American Heart Association. Circulation 2016; 133: e38-360.

3. Bui AL, Horwich TB, Fonarow GC. Epidemiology and risk profile of heart failure. Nat Rev Cardiol 2011; 8: 30-41.

4. $\mathrm{Ni} \mathrm{H}, \mathrm{Xu}$ J. Recent trends in heart failure-related mortality: United States, 2000-2014. NCHS Data Brief, no 231. Hyattsville, MD: National Center for Health Statistics. 2015.

5. Yancy CW, Jessup M, Bozkurt B, et al. 2013 ACCF/AHA guideline for the management of heart failure: executive summary: a report of the American College of Cardiology Foundation/American Heart Association Task Force on Practice Guidelines. Circulation 2013; 128 1810-52.

6. McMurray JJ, Packer M, Desai AS, et al. Angiotensinneprilysin inhibition versus enalapril in heart failure. N Engl J Med 2014; 371: 993-1004.

7. Davis RC, Hobbs FD, Lip GY. ABC of heart failure: history and epidemiology. BMJ 2000; 320: 39-42.

8. Rudolf RD. An Address on the treatment of chronic heart failure. Can Med Assoc 1925; 15: 17-20.

9. Arnott WM. Heart failure. Br Med J 1966; 1: 1585-7.

10. The CONSENSUS Trial Study Group. Effects of enalapril on mortality in severe congestive heart failure: results of the Cooperative North Scandinavian Enalapril Survival Study (CONSENSUS). N Engl J Med 1987; 316: 1429-35.

11. The SOLVD Investigators. Effect of enalapril on survival in patients with reduced left ventricular ejection fractions and congestive heart failure. N Engl J Med 1991; 325: 293-302.

12. MERIT-HF Study Group. Effect of metoprolol CR/XL in chronic heart failure: Metoprolol CR/XL Randomised Intervention Trial in Congestive Heart Failure (MERIT-HF). Lancet 1999; 353: 2001-7.

13. Packer M, Coats AJ, Fowler MB, et al. Effect of carvedilol on survival in severe chronic heart failure. N Engl J Med 2001; 344: 1651-8.

14. CIBIS-II Investigators and Committees. The Cardiac Insufficiency Bisoprolol Study II (CIBIS-II): a randomised trial. Lancet 1999; 353: 9-13.
15. Pitt B, Zannad F, Remme WJ, et al. The effect of spironolactone on morbidity and mortality in patients with severe heart failure. N Engl J Med 1999; 341: 709-17.

16. Pitt B, Remme W, Zannad F, et al. Eplerenone, a selective aldosterone blocker, in patients with left ventricular dysfunction after myocardial infarction. N Engl J Med 2003; 348: 1309-1321 [Erratum, N Engl J Med 2003; 348: 2271]

17. Zannad F, McMurray JJ, Krum H, et al. Eplerenone in patients with systolic heart failure and mild symptoms. N Engl J Med 2011; 364: 11-21.

18. Cohn JN, Tognoni G. A randomized trial of the angiotensin-receptor blocker valsartan in chronic heart failure. N Engl J Med 2001; 345: 1667-75.

19. Young JB, Dunlap ME, Pfeffer MA, et al. Mortality and morbidity reduction with candesartan in patients with chronic heart failure and left ventricular systolic dysfunction: results of the CHARM low-left ventricular ejection fraction trials. Circulation 2004; 110: 2618-26.

20. Taylor AL, Ziesche S, Yancy C, et al. Combination of isosorbide dinitrate and hydralazine in blacks with heart failure. N Engl J Med 2004; 351: 2049-57.

21. Stingo AJ, Clavell AL, Aarhus LL, et al. Cardiovascular and renal actions of C-type natriuretic peptide. Am J Physiol 1992; 262: H308-12.

22. Levin ER, Gardner DG, Samson WK. Natriuretic peptides. N Engl J Med 1998; 339: 321-8.

23. Soeki T, Kishimoto I, Okumura H, et al. C-type natriuretic peptide, a novel antifibrotic and antihypertrophic agent, prevents cardiac remodeling after myocardial infarction. J Am Coll Cardiol 2005; 45: 608-16.

24. Mangiafico S, Costello-Boerrigter LC, Andersen IA, et al. Neutral endopeptidase inhibition and the natriuretic peptide system: an evolving strategy in cardiovascular therapeutics. Eur Heart J 2013; 34: 886c-93c.

25. Hamaguchi S, Kinugawa S, Tsuchihashi-Makaya M, et al. Characteristics, management, and outcomes for patients during hospitalization due to worsening heart failure - A report from the Japanese Cardiac Registry of Heart Failure in Cardiology (JCARE-CARD). J Cardiol 2013; 62: 95-101.

26. Colucci WS, Elkayam U, Horton DP, et al. Intravenous nesiritide, a natriuretic peptide, in the treatment of decompensated congestive heart failure. N Engl J Med 2000; 343: 246-53.

27. Publication Committee for the VMAC Investigators. Intravenous nesiritide vs nitroglycerin for treatment of decompensated congestive heart failure: a randomized controlled trial. JAMA 2002; 287: 1531-40.

28. O'Connor CM, Starling RC, Hernandez AF, et al. Effect of nesiritide in patients with acute decompensated heart failure. N Engl J Med 2011; 365: 32-43.

29. Yancy CW, Krum H, Massie BM, et al. Safety and efficacy of outpatient nesiritide in patients with advanced heart failure: results of the Second Follow-Up Serial Infusions of Nesiritide (FUSION II) trial. Circ Heart Fail 2008; 1: 9-16.

30. Chen HH, Anstrom KJ, Givertz MM, et al. Low-dose dopamine or low-dose nesiritide in acute heart failure with renal dysfunction: the ROSE acute heart failure randomized trial. JAMA 2013; 310: 2533-43.

31. Potter LR. Natriuretic peptide metabolism, clearance and degradation. FEBS J 2011; 278: 1808-17.

32. Turner AJ, Tanzawa K. Mammalian membrane metallopeptidases: NEP, ECE, KELL, and PEX. FASEB J 1997; 11: 355-64.

33. Braunwald E. The path to an angiotensin receptor antagonist-neprilysin inhibitor in the treatment of heart failure. J Am Coll Cardiol 2015; 65: 1029-41. 
34. Watanabe Y, Nakajima K, Shimamori Y, et al. Comparison of the hydrolysis of the three types of natriuretic peptides by human kidney neutral endopeptidase 24.11. Biochem Mol Med 1997; 61: 47-51.

35. Roques BP, Fournie-Zaluski MC, Soroca E, et al. The enkephalinase inhibitor thiorphan shows antinociceptive activity in mice. Nature 1980; 288: 286-8.

36. Sybertz EJ, Chiu PJS, Vemulapalli S, et al. SCH 39370 , a neutral metalloendopeptidase inhibitor, potentiates biological responses to atrial natriuretic factor and lowers blood pressure in desoxycorticosterone acetate-sodium hypertensive rats. J Pharmacol Exp Ther 1989; 250: 624-31.

37. Northridge DB, Jardine AG, Alabaster CT, et al. Effects of UK 69 578: a novel atriopeptidase inhibitor. Lancet 1989; 2: 591-3.

38. Martin FL, Stevens TL, Cataliotti A, et al. Natriuretic and antialdosterone actions of chronic oral NEP inhibition during progressive congestive heart failure. Kidney Int 2005; 67: 1723-30.

39. Munzel T, Kurz S, Holtz J, et al. Neurohormonal inhibition and hemodynamic unloading during prolonged inhibition of ANF degradation in patients with severe chronic heart failure. Circulation 1992; 86: 1089-8.

40. Cleland JG, Swedberg K. Lack of efficacy of neutral endopeptidase inhibitor ecadotril in heart failure. Lancet 1998; 351: 1657-8.

41. Bevan EG, Connell JM, Doyle J, et al. Candoxatril, a neutral endopeptidase inhibitor: efficacy and tolerability in essential hypertension. J Hypertens 1992; 10: 607-13.

42. Ando S, Rahman MA, Butler GC, et al. Comparison of candoxatril and atrial natriuretic factor in healthy men. Effects on hemodynamics, sympathetic activity, heart rate variability, and endothelin. Hypertension 1995; 26 1160-6.

43. Ferro CJ, Spratt JC, Haynes WG, et al. Inhibition of neutral endopeptidase causes vasoconstriction of human resis tance vessels in vivo. Circulation 1998; 97: 2323-30.

44. Stephenson SL, Kenny AJ. Metabolism of neuropeptides. hydrolysis of the angiotensins, bradykinin, substance $P$ and oxytocin by pig kidney microvillar membranes. Biochem J 1987; 241: 237-47.

45. Newby DE, McDonagh T, Currie PF, et al. Candoxatril improves exercise capacity in patients with chronic heart failure receiving angiotensin converting enzyme inhibition. Eur Heart J 1998; 19: 1808-13.

46. Seymour AA, Swerdel JN, Abboa-Offei B. Antihypertensive activity during inhibition of neutral endopeptidase and angiotensin converting enzyme. J Cardiovasc Pharmacol 1991; 17: 456-65.

47. Seymour AA, Asaad MM, Lanoce VM, et al. Systemic hemodynamics, renal function and hormonal levels during inhibition of neutral endopeptidase 3.4.24.11 and angiotensin-converting enzyme in conscious dogs with pacing-induced heart failure. J Pharmacol Exp Ther 1993; 266: 872-83.

48. Rademaker MT, Charles CJ, Espiner CJ, et al. Combined neutral endopeptidase and angiotensin-converting enzyme inhibition in heart failure: role of natriuretic peptides and angiotensin II. J Cardiovasc Pharm 1998; 31: 116-25.

49. Fournie-Zaluski MC, Coric P, Turcaud S, et al. New dual inhibitors of neutral endopeptidase and angiotensin-converting enzyme: rational design, bioavailability, and pharmacological responses in experimental hypertension. J Med Chem 1994; 37: 1070-83.

50. Sagnella GA. Vasopeptidase inhibitors. J Renin Angiotensin Aldosterone Syst 2002; 3: 90-5.
51. McClean DR, Ikram H, Garlick AH, et al. The clinical, cardiac, renal, arterial and neurohormonal effects of omapatrilat, a vasopeptidase inhibitor, in patients with chronic heart failure. J Am Coll Cardiol 2000; 36: 479-86.

52. Rouleau JL, Pfeffer MA, Stewart DJ, et al. Comparison of vasopeptidase inhibitor, omapatrilat, and lisinopril on exercise tolerance and morbidity in patients with heart failure: IMPRESS randomised trial. Lancet 2000; 356: 615-20.

53. Eisenstein EL, Nelson CL, Simon TA, et al. Vasopeptidase inhibitor reduces inhospital costs for patients with congestive heart failure: results from the IMPRESS trial. Inhibition of metallo protease by BMS-186716 in a randomized exercise and symptoms study in subjects with heart failure. Am Heart J 2002; 143: 1112-7.

54. Packer M, Califf RM, Konstam MA, et al. Comparison of omapatrilat and enalapril in patients With chronic heart failure: the Omapatrilat Versus Enalapril Randomized Trial of Utility in Reducing Events (OVERTURE). Circulation 2002; 106: 920-6.

55. Kostis JB, Packer M, Black HR, et al. Omapatrilat and enalapril in patients with hypertension: the Omapatrilat Cardiovascular Treatment vs. Enalapril (OCTAVE) trial. Am J Hypertens 2004; 17: 103-11.

56. Israili ZH, Hall WD. Cough and angioneurotic edema associated with angiotensin-converting enzyme inhibitor therapy. A review of the literature and pathophysiology. Ann Intern Med 1992; 117: 234-42.

57. Nussberger J, Cugno M, Amstutz C, et al. Plasma bradykinin in angio-oedema. Lancet 1998; 351: 1693-7.

58. Sulpizio AC, Pullen MA, Edwards RM, et al. Mechanism of vasopeptidase inhibitor-induced plasma extravasation: comparison of omapatrilat and the novel neutral endopeptidase 24.11/angiotensin-converting enzyme inhibitor GW796406. J Pharmacol Exp Ther 2005; 315: 1306-13.

59. Fryer RM, Segreti J, Banfor PN, et al. Effect of bradykinin metabolism inhibitors on evoked hypotension in rats: rank efficacy of enzymes associated with bradykinin-mediated angioedema. Br J Pharmacol 2008; 153 : 947-55.

60. Hegde LG, Yu C, Renner T, et al. Concomitant angiotensin AT1 receptor antagonism and neprilysin inhibition produces omapatrilat-like antihypertensive effects without promoting tracheal plasma extravasation in the rat. J Cardiovasc Pharmacol 2011; 57: 495-504.

61. Gu J, Noe A, Chandra P, et al. Pharmacokinetics and pharmacodynamics of LCZ696, a novel dual-acting angiotensin receptor - neprilysin inhibitor (ARNi). J Clin Pharmacol 2010; 50: 401-14.

62. Hegde LG, Yu C, Madhavi C, et al. Comparative efficacy of AHU-377, a potent neprilysin inhibitor, in two rat models of volume-dependent hypertension. BMC Pharmacol 2011; 11: P33.

63. Ruilope LM, Dukat A, Bohm M, et al. Blood-pressure reduction with LCZ696, a novel dual-acting inhibitor of the angiotensin II receptor and neprilysin: a randomised, double-blind, placebo-controlled, active comparator study. Lancet 2010; 375: 1255-66.

64. Kario K, Sun N, Chiang FT, et al. Efficacy and safety of LCZ696, a first-in-class angiotensin receptor neprilysin inhibitor, in Asian patients with hypertension: a randomized, double-blind, placebo-controlled study. Hypertension 2014; 63: 698-705.

65. Solomon SD, Zile M, Pieske B, et al. The angiotensin receptor neprilysin inhibitor LCZ696 in heart failure with preserved ejection fraction: a phase 2 double-blind randomised controlled trial. Lancet 2012; 380: 1387-95. 
66. Martinez-Rumayor A, Richards AM, Burnett JC, et al. Biology of the natriuretic peptides. Am J Cardiol 2008; 101: 3-8

67. Jhund PS, Claggett B, Packer M, et al. Independence of the blood pressure lowering effect and efficacy of the angiotensin receptor neprilysin inhibitor, LCZ696, in patients with heart failure with preserved ejection fraction: an analysis of the PARAMOUNT trial. Eur J Heart Fail 2014; 16: 671-7.

68. McMurray J, Packer M, Desai AS, et al. A putative placebo analysis of the effects of LCZ696 on clinical outcomes in heart failure. Eur Heart J 2015; 36: 434-9.

69. Packer M, McMurray JJ, Desai AS, et al. Angiotensin receptor neprilysin inhibition compared with enalapril on the risk of clinical progression in surviving patients with heart failure. Circulation 2015; 131: 54-61.

70. Desai AS, McMurray JJ, Packer M, et al. Effect of the angiotensin-receptor-neprilysin inhibitor LCZ696 compared with enalapril on mode of death in heart failure patients. Eur Heart J 2015; 36: 1990-7.

71. Kristensen SL, Preiss D, Jhund PS, et al. Risk related to pre-diabetes mellitus and diabetes mellitus in heart failure with reduced ejection fraction: insights from prospective comparison of ARNI with ACEI to determine impact on global mortality and morbidity in heart failure trial. Circ Heart Fail 2016; 9: e002560.

72. Solomon S, Packer $M$, Zile $M$, et al. The angiotensin receptor neprilysin inhibitor LCZ696 is effective across the spectrum of ejection fraction in heart failure with reduced ejection fraction. J Card Fail 2015; 21: S45-6.

73. Simpson J, Jhund PS, Silva Cardoso J, et al. Comparing LCZ696 with enalapril according to baseline risk using the MAGGIC and EMPHASIS-HF risk scores: an analysis of mortality and morbidity in PARADIGM-HF. J Am Coll Cardiol 2015; 66: 2059-71.

74. Böhm M, Refsgaard J, Ramires FJ, et al. Effect of angiotensin receptor neprilysin inhibitor LCZ696 compared with enalapril according to systolic blood pressure in PARADIGM-HF. Eur J Heart Fail 2015; 17 (Suppl. 1): 393.

75. Jhund PS, Fu M, Bayram E, et al. Efficacy and safety of LCZ696 (sacubitril-valsartan) according to age: insights from PARADIGM-HF. Eur Heart J 2015; 36: 2576-84.

76. von Lueder TG, Wang BH, Kompa AR, et al. Angiotensin receptor neprilysin inhibitor LCZ696 attenuates cardiac remodeling and dysfunction after myocardial infarction by reducing cardiac fibrosis and hypertrophy. Circ Heart Fail 2015; 8: 71-8

77. Suematsu Y, Miura S, Goto M, et al. LCZ696, an angiotensin receptor-neprilysin inhibitor, improves cardiac function with the attenuation of fibrosis in heart failure with reduced ejection fraction in streptozotocin-induced diabetic mice. Eur J Heart Fail 2016; 18: 386-93.

78. Nalivaeva NN, Belyaev ND, Kerridge C, et al. Amyloid-clearing proteins and their epigenetic regulation as a therapeutic target in Alzheimer's disease. Front Aging Neurosci 2014; 6: 235-5.

79. Vodovar N, Paquet C, Mebazaa A, et al. Neprilysin, cardiovascular, and Alzheimer's diseases: the therapeutic split? Eur Heart J 2015; 36: 902-5.

80. Moe GW, Ezekowitz JA, O'Meara E, et al. The 2014 Canadian Cardiovascular Society Heart Failure Management Guidelines focus update: anemia, biomarkers, and recent therapeutic trial implications. Can J Cardiol 2015; 31: 3-16.

81. Williams B, Cockcroft JR, Kario K, et al. Principal results of the prospective comparison of angiotensin receptor neprilysin inhibitor with angiotensin receptor blocker measuring arterial stiffness in the elderly (PARAMETER) study. European Society of Cardiology 2015 Congress; August 31, 2015; London, UK. Abstract 4143.

82. Judge P, Haynes R, Landray MJ, et al. Neprilysin inhibition in chronic kidney disease. Nephrol Dial Transplant 2015; 30: 738-43. 